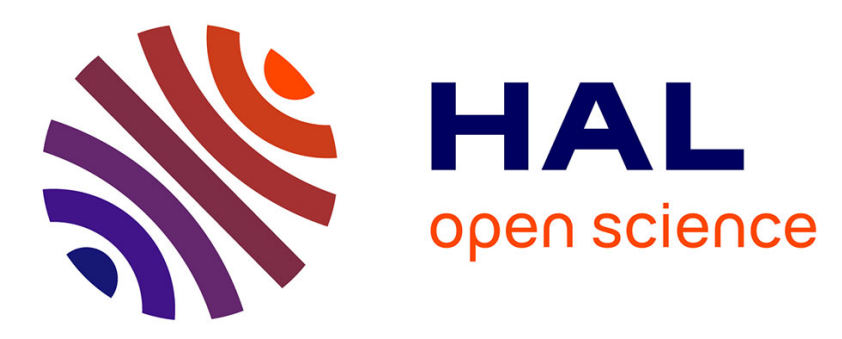

\title{
Surgical treatment of hypothalamic hamartomas
}

Pierre Bourdillon, S. Ferrand-Sorbet, C. Apra, M. Chipaux, E. Raffo, S.

Rosenberg, C. Bulteau, N. Dorison, O. Bekaert, V. Dinkelacker, et al.

\section{To cite this version:}

Pierre Bourdillon, S. Ferrand-Sorbet, C. Apra, M. Chipaux, E. Raffo, et al.. Surgical treatment of hypothalamic hamartomas. Neurosurgical Review, 2021, 44 (2), pp.753-762. 10.1007/s10143-02001298-z . hal-03265578

\section{HAL Id: hal-03265578 \\ https://hal.sorbonne-universite.fr/hal-03265578}

Submitted on 21 Jun 2021

HAL is a multi-disciplinary open access archive for the deposit and dissemination of scientific research documents, whether they are published or not. The documents may come from teaching and research institutions in France or abroad, or from public or private research centers.
L'archive ouverte pluridisciplinaire HAL, est destinée au dépôt et à la diffusion de documents scientifiques de niveau recherche, publiés ou non, émanant des établissements d'enseignement et de recherche français ou étrangers, des laboratoires publics ou privés. 


\section{Surgical treatment of hypothalamic hamartomas}

P. Bourdillon ${ }^{1,2,3,4 *}$, S. Ferrand-Sorbet ${ }^{2 *}$, C. Apra ${ }^{3,4,5}$, M. Chipaux ${ }^{2}$, E. Raffo ${ }^{2,6}$, S. Rosenberg $^{2}$, C. Bulteau ${ }^{2,7}$, N. Dorison ${ }^{2}$, O. Bekaert ${ }^{2}$, V. Dinkelacker ${ }^{8}$, C. Le Guérinel ${ }^{1}$, M. Fohlen ${ }^{2}$, G. Dorfmüller ${ }^{2}$

1. Department of neurosurgery, Adolphe de Rothschild Foundation, Paris, France.

2. Department of pediatric neurosurgery, Adolphe de Rothschild Foundation, Paris, France.

3. Sorbonne Université, Paris, France.

4. Brain and Spine Institute, INSERM U1127, CNRS, UMR7225, Paris, France.

5. Department of neurosurgery, Pitié-Salpêtrière Hospital, Paris, France.

6. Université de Lorraine, Nancy, France.

7. Université de Paris, Paris, France

8. Department of neurology, Adolphe de Rothschild Foundation, Paris, France.

* These authors equally contributed to this work

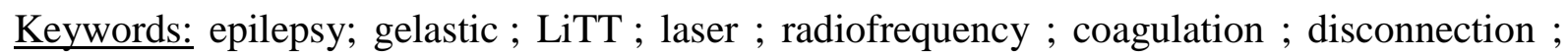
stereotactic

Sources of financial and material support: No specific funding was received for this work. None of the authors declare disclosure

Corresponding author:

Pierre Bourdillon

Department of Neurosurgery, Fondation Adolphe de Rothschild, 29 Rue Manin, 75019, Paris, France

Phone: (+33) 148036565

pierre.bourdillon@neurochirurgie.fr 


\begin{abstract}
Hypothalamic hamartomas are aberrant masses, composed of abnormally distributed neurons and glia. Along endocrine and cognitive symptoms, they may cause epileptic seizures, including the specific gelastic and dacrystic seizures. Surgery is the treatment of drug resistant hamartoma epilepsy, with associated positive results on endocrine, psychiatric and cognitive symptoms. Recently, alternatives to open microsurgical treatment have been proposed. We review these techniques and compare their efficacy and safety.
\end{abstract}

Open resection or disconnection of the hamartoma, either through pterional, transcallosal or transventricular approach, leads to good epileptological control but its high complication rate, up to $30 \%$, limits its indications. The purely cisternal peduncular forms remain the only indication of open, pterional, approach, while other strategies have been developed to overcome the neurological, endocrine, behavioral or cognitive complications.

Laser and radiofrequency thermo-coagulation based disconnection through robot-guided stereo-endoscopy has been proposed as an alternative to open microsurgical resection and stereotactic destruction. The goal is to allow safe and complete disconnection of a possibly complex attachment zone, through a single intraparenchymal trajectory which allows multiple laser or radiofrequency probe trajectory inside the ventricle. The efficacy was high, with $78 \%$ of favorable outcome, and the overall complication rate was $8 \%$. It was especially effective in patients with isolated gelastic seizures and pure intraventricular hamartomas.

Stereotactic radiosurgery has proved as efficacious and safer than open microsurgery, with around $60 \%$ of seizure control and a very low complication rate. Multiple stereotactic thermocoagulation showed very interesting results with $71 \%$ of seizure freedom and $2 \%$ of permanent complications. Stereotactic laser interstitial thermotherapy (LiTT) seems as effective as open microsurgery (from $76 \%$ to $81 \%$ of seizure freedom) but causes up to $20 \%$ of permanent complications. This technique has however been highly improved by targeting only the epileptogenic onset zone in the hamartoma, as shown on preoperative functional MRI, leading to an improvement of epilepsy control by $45 \%$ ( $92 \%$ of seizure freedom) with no postoperative morbidity.

All these results suggest that the impact of the surgical procedure does not depend on purely technical matters (laser vs radiofrequency thermo-coagulation or stereotactic vs robot-guided stereo-endoscopy) but relies on the understanding of the epileptic network, including inside the 
hamartoma, the aim being to plan an effective disconnection or lesion of the epileptogenic part

1

2

3

4

5

6

7

8

9

10

11

12

13

14

15

16

17

18

19

20

21

22

23

24

25

26

27

28

29

30

31

32

33

34

35

36

37

38

39

40

41

42

43

44

45

46

47

48

49

50

51

52

53

54

55

56

57

58

59

60

61

62

63

64

65 while sparing the adjacent functional structures. 


\section{Introduction}

Hypothalamic hamartomas (from $\dot{\alpha} \mu \alpha \rho \tau i \alpha, \sin )$ are rare heterotopic masses resulting from an aberrant development of normal tissue that arise from the ventral hypothalamus ${ }^{40}$. They are composed of abnormally distributed but cytologically normal neurons and glia, including fibrillary astrocytes and oligodendrocytes 19,46. Hypothalamic hamartomas can be isolated, associated with other brain lesions, or be part of malformative disorders, for instance the Pallister-Hall syndrome, a genetic disease caused by GLI3 frameshift mutations ${ }^{38}$. These developmental malformations can be diagnosed incidentally ${ }^{16}$ or during investigation of neurological, psychiatric or endocrine disturbances ${ }^{46}$ according to their anatomical location. When the lesion is in contact with the infundibulum or with the tuber cinereum, endocrine signs are frequently present, especially precocious puberty ${ }^{17}$. Epilepsy and behavioral or cognitive disorders are associated with hypothalamic hamartomas connected with the mamillary bodies $^{55,76}$. Epilepsy usually starts during the first year of life with the classical gelastic seizures $^{46}$ (from $\gamma \varepsilon \dot{\lambda} \omega \varsigma$, laugh) or less frequently dacrystic (from $\delta \alpha ́ \kappa \rho v$, tear) seizures ${ }^{12}$. These very specific seizures have first been reported during the late XIX $^{\text {th }}$ century by Armand Trousseau ${ }^{75}$ as an "irrepressible pulsion to laugh". The term "gelastic" was introduced in $1957^{21}$, and description of gelastic attacks defined in 1971 as "characterized by repeated shortlasting seizures with initial emotionless laughter or grimacing"30,46. These seizures are difficult to identify as the symptoms can easily been misinterpreted and the diagnosis if often delayed when the child develops other types of seizures ${ }^{32}$ such as drop attacks, generalized tonicoclonic seizures, complex partial seizures, frequently associated with psychiatric disorders or cognitive impairement $t^{5,28,56}$. This evolution strongly suggests a secondary epileptogenesis that involves mainly frontal and temporal structures, strongly connected with hypothalamic region ${ }^{29,49}$. Since the first clinical description of a positive effect of hamartoma surgery on epilepsy $^{53}$, many evidence of the implication of the lesion in the epileptic network have been provided in stereoelectroencephalography $(\mathrm{SEEG})^{35,36,50}$. Beyond the strong evidence for the intrinsic epileptogenesis of the hamartomas strengthened by metabolic neuroimaging studies $^{41,66}$, non-gelastic seizures may indicate an implication of temporal and frontal regions in the epileptic network ${ }^{67}$. These seizures can be independent from discharges from the hypothalamic hamartoma itself ${ }^{32}$. Alongside the description of the multiple aspects of the epileptic networks in hypothalamic hamartomas related epilepsy, many surgical techniques have been developed, including open, endoscopic and stereotactic techniques making it uneasy to have a clear overview of the available therapeutic possibilities. 
We conducted a narrative review of the surgical treatments of hypothalamic hamartomas by conducting a Pubmed/MEDLINE literature search up to November 2019 with the terms: 'hypothalamic hamartoma', AND 'epilepsy', 'seizure', 'gelastic', 'precocious puberty', 'secondary epileptogenesis', 'epileptic network'. We selected original papers with patients data based on their importance in the field.

\section{Focusing on the hamartoma}

Hypothalamic hamartomas have a non-complex microarchitecture with many nodular groups of neurons of which $80 \%$ have an interneuron-like phenotype and express glutamic acid decarboxylase ${ }^{19}$. These neurons utilizing $\gamma$-aminobutyric acid as primary neurotransmitter have membrane features that make them have a spontaneous pacemaker-like firing activity. These predominant population of firing neurons is associated to large pleomorphic pyramidal neurons appearing to be excitatory projection having the functionally immature behavior of depolarizing and firing in response to GABA ligands ${ }^{40}$. These characteristics fit well with the hypothesis of a key role of hypothalamic hamartomas in the ictogenesis and the triggering of seizures that spread to a larger and diffuse epileptic network. This hypothesis has been strengthened by SEEG data ${ }^{35,36,50}$, and justifies the surgical development targeting directly the hypothalamic hamartoma.

However, hypothalamic hamartomas have also been considered as a model of human secondary epileptogenesis ${ }^{67}$ at least for the two first stages according to the Morrel models : epileptiform discharges detected in the secondary focus were driven by the primary focus, whose destruction resulted in immediate cessation of epileptogenic discharges (first stage) ; independent seizures and interictal epileptiform discharges detected in the secondary focus that initially persist after removal of the primary focus, but eventually disappeared spontaneously later (second stage) ${ }^{77}$. This secondary epileptogenesis justifies an early surgical treatment of hypothalamic hamartoma related epilepsy and fits with the better seizure control reported in literature when surgery is precocious in the natural history of the disease ${ }^{26,37}$. Recent data suggested that the third stage, corresponding to a persistent long-term epileptiform activity in the secondary epileptogenic area after removal of the primary focus, may occur in hypothalamic hamartoma related epilepsy ${ }^{67}$. Consequently, phase I investigation suggesting a cingulate, a frontal or a 
temporal independent network should make consider, especially in case of long medical history

\section{Surgical techniques}

Several surgical classifications have been proposed to orientate the best surgical approach and to predict the functional and epileptic outcome after the surgery. The original classification of 1991 distinguishing the peduncular from the sessile hypothalamic hamartomas ${ }^{11}$ was refined in two sub categories each by Valdueza ( $1 \mathrm{a}$ and $1 \mathrm{~b}$ for peduncular and $2 \mathrm{a}$ and $2 \mathrm{~b}$ for sessile hamartomas $)^{76}$. Arita proposed a close classification that separates the parahypothalamic (usually the peduncular ones) from the intrahypothalamic (usually the sessile ones) hypothalamic hamartomas ${ }^{3}$. More complex classifications have been proposed, especially by Regis $^{60}$ and $\mathrm{Shim}^{70}$, but Delalande's classification into four subtypes ${ }^{22}$ remains the most used ${ }^{46}$ (Figure 1). Type I are small peduncular lesions characterized by an horizontal plane of attachment to the tuber cinereum ; Type II are mainly intraventricular lesions having a vertical plane of insertion ; Type III lesions are a combination of Types I and II having both an horizontal and a vertical insertion plane ; Type IV lesions are generally very large tumors with broad attachment to both the mammillary bodies and the hypothalamus and have an extension into the interpeduncular cistern. 


\section{Open disconnection and resection surgery}

Since the first description of a surgical treatment of an hypothalamic hamartoma in $1969^{53}$, the discussion has been dominated by the opposition between two micro-neurosurgical techniques: one aiming to reach the lesion from below (pterional and transtemporal-transchoroidal approaches), versus another aiming to reach the lesion from above (transcallosal and transventricular) ${ }^{7,46,64}$. Whatever the technique (Figure 2), the possibility of complete removal is correlated to the importance of the attachment to the mamillary bodies (neuropsychological risk) and to the tuber cinereum (endocrine risk) ${ }^{62}$.

The pterional approach is the shortest and most direct route to the suprasellar cistern but the access to the third ventricle and the intraventricular component of the hypothalamic hamartoma is limited by the narrowness of the surgical corridor constituted by the carotid artery, optic nerve and chiasm, third cranial nerve, and infundibulum ${ }^{47}$. Although the reported seizure control is higher than $90 \%$ in some series, the morbidity is important, including transient third nerve palsy, thalamo-capsular infarcts, postoperative central diabetes insipidus, and hyperphagia. ${ }^{47}$ These limits lead to the development of alternative surgical approaches reaching the lesion from above $^{7,46,64}$. This technique was associated with good resection results for intraventricular lesions (Delalande Type II and IV) but remained limited in case of cisternal expension of the lesion. In the review by Mittal and al. The complication rate reported was still high, the risk of memory impairment was increased ${ }^{47}$. Although new technologic advances have been used, including per-operative MRI, and succeded in increasing the seizure free rate above $80 \%$, the complication rate remains high, greater than $30 \%{ }^{78}$. Concomitantly and with the similar objective to reach the lesion from above, a transcallosal transeptal interfornical approach has been introduce in $2001^{63}$ offering a wide exposition of the hypothalamic hamartoma. While the risk of cerebral infarction and oculomotor nerve palsy is reduced by avoiding manipulation of the vessels in the suprasellar and interpeduncular cistern, as well as the risk of injury to the mammillary bodies, pituitary stalk, the inherent risk is a fornical damage causing memory deficit $^{48,52}$. Three larges series totalizing 92 patients have been reported. Seizure frequency reduction was acheved in more than $90 \%$ and seizure freedom in between 50 to $55 \%$ of them. The most common complications were thalamic infarction and memory impairement (wich was permanent in less than $10 \%$ of patients) but were conterbalanced by both cognitive and behavhioral improvements (respectively $88 \%$ and $60 \%$ of patients). A correlation between completeness of excision of the hypothalamic hamartoma and seizure freedom have been demonstrated. Interestingly the memory impairement was higher in older patient, possibly as a 
consequence from forniceal injury because the leaves of the septum pellucidum are not as easily separated $^{47,52,78,83}$. In this context endoscopic approach has been introduced by Akai in 2002 and then popularized by the Barrow Neurological Institute group from $2006^{2} z 006^{45}$. Between $48 \%$ and $58 \%$ of patients of the two largest published series were seizure free ${ }^{18,51}$ but major complications remain high ${ }^{51}$ in one of them. To overcome this issue, the Cappabianca group proposed through a comprehensive review ${ }^{14}$ to limit the endoscopic resection to the small hypothalamic hamartoma with a unilateral attachment to the hypothalamic wall with at least 6 $\mathrm{mm}$ between the top of the lesion and the roof of the third ventricle.

\section{Stereotactic radiosurgery}

Stereotactic radiosurgery by Gamma Knife as a treatment of hypothalamic hamartomas was first reported in 1998 for a single young patient having a long history of hypothalamic hamartoma related drug resistant epilepsy ${ }^{4}$. The encouraging functional results of the treatment have been promptly followed by a series reported by Regis ${ }^{57}$ and a prospective multicentric study in which $25 \mathrm{~Gy}$ was delivered to the $50 \%$ isodose line ${ }^{58}$. Despite the usual delayed action of the radiosurgery, the results were very promising as only a minor complication happened (5 months long hyperthermia) and $26 \%$ of patients were seizure free. The median number of seizures per month was reduce from 6.2 to 0.3 . The median marginal dose was $17 \mathrm{~Gy}$ (range, 14 to 20). The long-term outcome on the study, in which 60 patients were enrolled, was published in 2006 and reported 31 patients with a minimum of three years follow up after the radiosurgery. The marginal isodose was $17 \mathrm{~Gy}$ (range, 13 to 26) and beam blocking strategies was used to minimize the dose delivered to the frail structures surrounding the hypothalamic hamartoma (mammillary bodies, fornices, visual pathways, tuber cinereum and pituitary stalk) ${ }^{60}$. None of the patients presented permanent complications but $15 \%$ of them experienced a temporary worsening of seizures. $37 \%$ of patients were seizure free and another $22 \%$ had a significant reduction of seizures frequency. The best result was obtained in a patient having a small type II hypothalamic hamartoma.

Among the increasing literature evaluating radiosurgery since this first promising studies ${ }^{1,15,43,59-61}$, two level 2 prospective studies reported respectively $60 \%{ }^{60}$ and $66 \%{ }^{43}$ of seizure control following radiosurgery. Furthermore, a progressive positive effect on behavior during the 6 following months, co-occurring with sleep patterns and EEG normalization was described $^{61}$. No major adverse event was reported, especially concerning the endocrine function ${ }^{15}$, except transient seizure control worsening and poikilothermia. More recently, these results 


\section{Stereotactic laser interstitial thermotherapy}

Laser interstitial thermotherapy (LiTT) consists in stereotactic placement of a laser probe through which a thermal lesion can be performed (Figure 3). The technique has initially been introduced in neuro-oncology as an alternative to open surgery ${ }^{45,69}$ but has been adapted to epilepsy surgery as early as $1978^{33,39}$. Commercialization of LiTT coupled to MRI monitoring through the Visualase $\AA^{81}$ and the NeuroBlate ${ }^{80}$ system causes a growing interest for the technique and the multiplication of the publication of series.

As the technique requires a small diameter trephination through a tiny skin incision and a short stay at hospital, the technique is frequently presented as a minimally invasive technique. However, the complication rate in literature review, $3.4 \%$ of severe complications and $23.5 \%$ of overall complications ${ }^{34}$, does not differ from the reported rate in open epilepsy surgery ${ }^{65}$. 
The recent introduction of this technique makes possible that this complication rate could be the result of a learning curve and could be expected to decrease in time. In the context of a high potential of this technique in epilepsy surgery, specific series on hypothalamic hamartomas have been published (Figure 4).

The University of California in San Francisco group introduced the technique and reported a seizure free rate of $60 \%$ associated to $20 \%$ of adverse effects on a series of 5 patients ${ }^{73}$. A first large literature review ${ }^{81}$ on 22 procedures with a mean follow-up of 17.4 months revealed that $80 \%$ of patients having gelastic seizures were seizure free after treatment and $56 \%$ of other patients had the same results. Immediate complication rate was $39 \%$ and $22 \%$ of patients had a permanent deficit, including hypothyroidism, short-term memory loss and weight gain. More recently, very experienced teams started publishing their results on large single center series. The series of the Texas Children's Hospital reported 71 patients. Among patients having more than one year follow-up, $78 \%$ were free of gelastic seizures and $12 \%$ were seizure free. $20 \%$ of patients needed a repeated treatment. The complication rate was $5.4 \%^{20}$. The Northwell Hospital group in New York reported a series of 8 patients and obtained a seizure free rate of $75 \%$ and a permanent complication rate of $12.5 \%{ }^{24}$.

Interestingly, the Barrow Neurological Institute group at Phoenix Children's Hospital developped a strategy going further than anatomical targeting for the LiTT in hypothalamic hamartomas (Figure 4) ${ }^{6}$. Although all neurons within the lesion are abnormal, some of them do not communicate outside of the hypothalamic hamartoma, so it was suggested that a lesioning of the whole hypothalamic hamartoma may be unnecessary. In addition to the anatomical localization of the lesion, data obtained by functional fMRI were taken into account. These data corresponded to the whole-brain functional connectivity of every individual hypothalamic hamartoma voxel. Images that showed connectivity between the hypothalamic hamartoma and any portion of the rest of the brain were considered as a part of the epileptic network. Subcentimeter targets obtained by resting state fMRI were then defined. The results of this approach have been reported through a 51 patients controlled study including 15 control patients and 36 patients undergoing the above described procedure. Results were significantly better in the fMRI targeted group (overall seizure reduction 85\%, Engel I 92\%) than in the control group (overall seizure reduction 49\%, Engel I 45\%). No postoperative morbidity or mortality occurred in the fMRI targeted group. 
This approach improved freedom from seizures by $45 \%$ compared to conventional ablation,

\section{Stereotactic radiofrequency coagulation}

Stereotactic radiofrequency thermocoagulation in epilepsy surgery has been introduced during the second half of the $\mathrm{XX}^{\text {th }}$ century ${ }^{68}$ originally for the treatment of temporal lobe epilepsy. The extension of this technique to the specific indication of hypothalamic hamartomas is more recent $^{37,42,54}$.

The most important contribution in this area comes from the Nishi-Niigata group in Japan ${ }^{37}$ who reported 140 consecutive procedures of MRI-guided stereotactic radiofrequency thermocoagulation for hypothalamic hamartomas over 100 patients (Figure 4). The median follow-up was 3 years (range, 1 to17) and only $10 \%$ of patients had pure gelastic seizures. $86 \%$ of patients were free of gelastic seizures and the overall seizure freedom rate was $71 \%$. This result was obtained with a median of 4 trajectories (range, 1 to 10) and 6 lesions (range, 1-36) per procedure. Permanent endocrine deficit concerned $2 \%$ of patients and required replacement therapy for hypocortisolism, hypothyroidism or diabetes insipidus. The rate of transient complications was high with $60.0 \%$ of Horner's syndrome, $27.9 \%$ of hyperphagia, $22.1 \%$ of hyponatremia, $22.1 \%$ of hyperthermia, $8.6 \%$ of short-term memory disturbance, $0.7 \%$ of disturbance of consciousness. $32 \%$ of patients required multiple procedures. It is worth noticing that the cognitive outcome has been specifically studied and was improved after stereotactic radiofrequency coagulation of the hamartoma ${ }^{72}$. Similar results were reported in 2003 in a series of 12 children $^{42}$ (but 6 patients underwent simultaneously an endoscopic treatment making the results hardly comparable) and in a series of 5 patients $^{74}$.

More recently and similarly to the functional connectivity approach developed for the superselective LiTT treatment ${ }^{6}$, SEEG-guided radiofrequency-thermocoagulation (SEEG-guided RF-TC) has been proposed for the hypothalamic hamartoma treatment ${ }^{79}$. SEEG-guided RF-TC consists of coupling SEEG investigation with RF-TC stereotactic lesioning directly through the recording electrodes ${ }^{10}$ and is valuable in epilepsy surgery ${ }^{9}$, especially to treat periventricular nodular heterotopia ${ }^{8}$, a pathology sharing a lot of similarities with hypothalamic hamartoma. Over a series of 9 patients, results were in the same range than conventional stereotactic radiofrequency coagulation ${ }^{79}$. However, such an indication requires to be carefully justified, as 
phase II investigations can be unnecessary to investigate hypothalamic hamartoma related seizures.

\section{Endoscopic laser and radiofrequency coagulation treatment}

Robot assisted endoscopy to perform hypothalamic hamartomas disconnection as an alternative to the microsurgical removal and stereotactic destruction of the lesions was introduced in 2003 by Delalande ${ }^{22,27}$. Surgical excision of the lesion has indeed no interest from an oncological point of view and a disconnection, except for type I hypothalamic hamartoma, can be achieved less invasively by an endoscopic trans-ventricular approach ${ }^{23}$. Stereotactic lesions, either by LiTT or RF-TC, are also less invasive than open microsurgical technique but a probe can only produce a spherical or an oblong lesion. Hypothalamic hamartomas are not always a perfect fit with this volume and the attachment to the functional adjacent hypothalamic structure is usually planar. It could be difficult to obtain a safe and complete disconnection of such planar insertion by performing a curved lesion with a single trajectory. That is why multiple probe stereotactic placement have been proposed ${ }^{71}$. To overcome the necessity to perform multiple stereotactic trajectory, the endoscopic robot assisted approach, allow to perform a single intraparenchymal trajectory, known to be functionally safe, and to perform multiple intraventricular placements of a $\mathrm{RF}-\mathrm{TC}^{22}$ or laser ${ }^{13}$ probe. Such flexibility in probe placement make it possible to perform multiple small volume lesions of the attachment plan of the hamartoma, which make conceptually this technique safer regarding the function of the adjacent structure (Figure 4, Video 1 \& 2).

Efficacy and safety of this original approach has recently been reported through a large series reporting long term outcome ${ }^{25,26}$. Over the 136 patients reported ${ }^{25}, 112$ were chidren $^{26}$ among whom 2 were type I, 67 were type II, 31 were type III and 12 were type IV, according to Delalande's classification. The median follow-up was 4 years. For all hypothalamic hamartoma types, $77.6 \%$ of the patients had a favorable outcome (Engel $1+2$ outcome score) with $57.1 \%$ seizure-free (Engel 1). The best outcome was obtained in patients with type 2 hypothalamic hamartomas, (68.7\% Engel 1 and $85.1 \%$ Engel 1+2), which is in line with previous series. Patients with isolated gelastic seizures had a better outcome (Engel 1+2 in 90\%), as compared to those with other seizure types. Unsurprisingly, a short delay between hamartoma diagnosis and surgery was a factor for a good outcome. Similarly to stereotactic techniques, multiple procedures were frequently needed to achieve good results. The mean number of procedures 
required depended on the Delalande type: 1.50 for type I ; 1.52 for type II ; 1.84 for type III ; 2.46 for type IV.

The overall complication rate was $8.3 \%$, which is similar to available literature.

\section{Conclusion}

Surgery is the most effective treatment for drug resistant hypothalamic hamartoma related epilepsy and has to be as precocious as possible, regardless the technique ${ }^{20,26,37}$. Although open microsurgical resection leads to good epileptological outcomes, its high complication rate limits indications. Only Delalande's type I purely cisternal peduncular forms, when associated with drug-resistant epilepsy, remain a good indications to perform pterional approach ${ }^{23,47}$. Laser and radiofrequency coagulation procedures (Figure 4) are significant advances compared to the historical microsurgical procedures. Concerning the approaches making a lesion to the whole hypothalamic hamartoma, literature review suggests that multiple radiofrequency small lesions ${ }^{37}$ have a better efficacy and safety than LiTT $^{20,34}$, probably due to the difficulty of the latter technique to target the whole lesion while sparing the adjacent structures (Figure 4). Nevertheless, these statement is based on single center results and will probably be counterbalanced by the recent advances of super-selective lesions performed with LiTT $^{82}$. Disconnection approach by laser and radiofrequency coagulation in robot guided stereoendoscopy provides very good results in term of seizure control and safety, probably due to possibility to fully disconnect the lesion and to spare the adjacent structures by a planar section (Figure 4) $)^{25,26}$.

Going beyond the surgical technique, the analysis of the pathological functional connectivity of the hypothalamic hamartoma by resting state MRI made it possible to target a subpart of the lesion $^{6}$. This approach coupled with LiTT procedures showed excellent results in term of seizure control and safety (Figure 4$)^{6}$. These findings suggest that the true impact on the surgical results does not come from purely surgical technique (laser vs radiofrequency coagulation or stereotactic vs robot-guided stereo-endoscopy) but relies on the understanding of the epileptic network, including inside the epileptic hamartoma, that makes possible to plan a disconnection or a lesioning that spare the adjacent functional structures. 


\section{Ethical statement:}

- Funding: The authors have received no funding for this article

- Conflict of Interest: The authors declare no conflict of interest

- Ethical approval: This article does not contain any studies with human participant or animals and complies with French ethical standards

- Informed consent: This article does not contain any studies with human participants performed by any of the authors.

\section{References}

1. Abla AA, Shetter AG, Chang SW, Wait SD, Brachman DG, Ng Y-T, et al: Gamma Knife surgery for hypothalamic hamartomas and epilepsy: patient selection and outcomes. J Neurosurg 113 Suppl:207-14, 2010

2. Akai T, Okamoto K, lizuka H, Kakinuma H, Nojima T: Treatments of hamartoma with neuroendoscopic surgery and stereotactic radiosurgery: a case report. Minim Invasive Neurosurg 45:235-9, 2002

3. Arita K, Ikawa F, Kurisu K, Sumida M, Harada K, Uozumi T, et al: The relationship between magnetic resonance imaging findings and clinical manifestations of hypothalamic hamartoma. J Neurosurg 91:212-20, 1999

4. Arita K, Kurisu K, Iida K, Hanaya R, Akimitsu T, Hibino S, et al: Subsidence of seizure induced by stereotactic radiation in a patient with hypothalamic hamartoma. Case report. J Neurosurg 89:645-8, 1998

5. Berkovic SF, Andermann F, Melanson D, Ethier RE, Feindel W, Gloor P: Hypothalamic hamartomas and ictal laughter: evolution of a characteristic epileptic syndrome and diagnostic value of magnetic resonance imaging. Ann Neurol 23:429 39,1988

6. Boerwinkle VL, Foldes ST, Torrisi SJ, Temkit H, Gaillard WD, Kerrigan JF, et al: Subcentimeter epilepsy surgery targets by resting state functional magnetic resonance imaging can improve outcomes in hypothalamic hamartoma. Epilepsia 59:2284-2295, 2018 
7. Bourdillon P, Rheims S, Catenoix H, Montavont A, Ostrowsky-Coste K, Isnard J, et al: Malformations of cortical development: New surgical advances. Rev Neurol (Paris) 175:183-188, 2019

8. Bourdillon P, Cucherat M, Isnard J, Ostrowsky-Coste K, Catenoix H, Guénot M, et al: SEEG-guided radiofrequency thermo-coagulations in patients with focal epilepsy: A systematic review and meta-analysis. Epilepsia 59:00:1-9., 2018

9. Bourdillon P, Isnard J, Catenoix H, Montavont A, Rheims S, Ryvlin P, et al: Stereo electroencephalography-guided radiofrequency thermocoagulation (SEEG-guided RFTC) in drug-resistant focal epilepsy: Results from a 10-year experience. Epilepsia 58:85-93, 2017

10. Bourdillon P, Rheims S, Catenoix H, Montavont A, Ostrowsky-Coste K, Isnard J, et al: Surgical techniques: Stereoelectroencephalography-guided radiofrequencythermocoagulation (SEEG-guided RF-TC). Seizure:2019

11. Boyko OB, Curnes JT, Oakes WJ, Burger PC: Hamartomas of the tuber cinereum: CT, MR, and pathologic findings. Am J Neuroradiol 12:309-314, 1991

12. Burghardt T, Basha MM, Fuerst D, Mittal S: Crying with sorrow evoked by electrocortical stimulation. Epileptic Disord 15:72-5, 2013

13. Calisto A, Dorfmüller G, Fohlen M, Bulteau C, Conti A, Delalande O: Endoscopic disconnection of hypothalamic hamartomas: Safety and feasibility of robot-assisted, thulium laser-based procedures. J Neurosurg Pediatr 14:563-572, 2014

14. Cappabianca P, Cinalli G, Gangemi M, Brunori A, Cavallo LM, De Divitiis E, et al: Application of neuroendoscopy to intraventricular lesions. Neurosurgery 62:2008

15. Castinetti F, Brue T, Morange I, Carron R, Régis J: Gamma Knife radiosurgery for hypothalamic hamartoma preserves endocrine functions. Epilepsia 58:72-76, 2017

16. Celedin S, Kau T, Gasser J, Kraschl R, Sinzig M: Fetal MRI of a hypothalamic hamartoma in Pallister-Hall syndrome. Pediatr Neurol 42:59-60, 2010

17. Chan YM, Fenoglio-Simeone KA, Paraschos S, Muhammad L, Troester MM, Ng YT, et al: Central precocious puberty due to hypothalamic hamartomas correlates with anatomic features but not with expression of GnRH, TGF $\alpha$, or KISS1. Horm Res

Paediatr 73:312-319, 2010 
18. Chibbaro S, Cebula H, Scholly J, Todeschi J, Ollivier I, Timofeev A, et al: Pure endoscopic management of epileptogenic hypothalamic hamartomas. Neurosurg Rev 40:647-653, 2017

19. Coons SW, Rekate HL, Prenger EC, Wang N, Drees C, Ng Y, et al: The histopathology of hypothalamic hamartomas: study of 57 cases. J Neuropathol Exp Neurol 66:13141, 2007

20. Curry DJ, Raskin J, Ali I, Wilfong AA: MR-guided laser ablation for the treatment of hypothalamic hamartomas. Epilepsy Res 142:131-134, 2018

21. Daly DD, Mulder DW: Gelastic epilepsy. Neurology 7:189-92, 1957

22. Delalande O, Fohlen M: Disconnecting surgical treatment of hypothalamic hamartoma in children and adults with refractory epilepsy and proposal of a new classification.

Neurol Med Chir (Tokyo) 43:61-68, 2003

23. Dorfmüller G, Fohlen M, Bulteau C, Delalande O: Surgical disconnection of hypothalamic hamartomas. Neurochirurgie 54:315-319, 2008

24. Du VX, Gandhi S V., Rekate HL, Mehta AD: Laser interstitial thermal therapy: A first line treatment for seizures due to hypothalamic hamartoma? Epilepsia 58:77-84, 2017

25. Ferrand-Sorbets S, Fohlen M, Chipaux M, Nathalie D, Bekaert O, Taussig D, et al: Déconnexion endoscopique des hamartomes hypothalamiques chez les patients atteints d'épilepsie pharmacorésistante: population de 136 adultes et enfants, in Journées Françaises d'épilepsie. Lyon, 2018

26. Ferrand-sorbets S, Fohlen M, Delalande O, Zuber K, Chamard P, Taussig D, et al: Seizure outcome and prognostic factors for surgical management of hypothalamic hamartomas in children. Seizure:[in press.], 2020

27. Fohlen M, Lellouch A, Delalande O: Hypothalamic hamartoma with refractory epilepsy: surgical procedures and results in 18 patients. Epileptic Disord 5:267-73, 2003

28. Frattali CM, Liow K, Craig GH, Korenman LM, Makhlouf F, Sato S, et al: Cognitive deficits in children with gelastic seizures and hypothalamic hamartoma. Neurology $57: 43-46,2001$ 
29. Freeman JL, Coleman LT, Wellard RM, Kean MJ, Rosenfeld J V., Jackson GD, et al: MR Imaging and Spectroscopic Study of Epileptogenic Hypothalamic Hamartomas: Analysis of 72 Cases. Am J Neuroradiol 25:450-462, 2004

30. Gascon GG, Lombroso CT: Epileptic (gelastic) laughter. Epilepsia 12:63-76, 1971

31. Harrison VS, Oatman O, Kerrigan JF: Hypothalamic hamartoma with epilepsy: Review of endocrine comorbidity. Epilepsia 58:50-59, 2017

32. Harvey AS, Freeman JL: Epilepsy in Hypothalamic Hamartoma: Clinical and EEG Features. Semin Pediatr Neurol 14:60-64, 2007

33. Heppner F: [Experiences with the $\mathrm{CO} 2$ laser in surgery of the nervous system]. Zentralbl Neurochir 40:297-301, 303-4, 1979

34. Hoppe C, Helmstaedter C: Laser interstitial thermotherapy (LiTT) in pediatric epilepsy surgery. Seizure:2018

35. Jung H, Probst EN, Hauffa BP, Partsch CJ, Dammann O: Association of Morphological Characteristics with Precocious Puberty and/ or Gelastic Seizures in Hypothalamic Hamartoma. J Clin Endocrinol Metab 88:4590-4595, 2003

36. Kahane P, Ryvlin P, Hoffmann D, Minotti L, Benabid AL: From hypothalamic hamartoma to cortex: What can be learnt from depth recordings and stimulation?

Epileptic Disord 5:205-217, 2003

37. Kameyama S, Shirozu H, Masuda H, Ito Y, Sonoda M, Akazawa K: MRI-guided stereotactic radiofrequency thermocoagulation for 100 hypothalamic hamartomas. J Neurosurg 124:1503-12, 2016

38. Kang S, Graham JM, Olney AH, Biesecker LG: GLI3 frameshift mutations cause autosomal dominant Pallister-Hall syndrome. Nat Genet 15:266-268, 1997

39. Kelly PJ, Sharbrough FW, Kall BA, Goerss SJ: Magnetic Resonance Imaging-Based Computer-Assisted Stereotactic Resection of the Hippocampus and Amygdala in Patients With Temporal Lobe Epilepsy. Mayo Clin Proc 62:103-108, 1987

40. Kerrigan JF, Parsons A, Tsang C, Simeone K, Coons S, Wu J: Hypothalamic hamartoma: Neuropathology and epileptogenesis. Epilepsia 58:22-31, 2017

41. Kuzniecky R, Guthrie B, Mountz J, Bebin M, Faught E, Gilliam F, et al: Intrinsic 
epileptogenesis of hypothalamic hamartomas in gelastic epilepsy. Ann Neurol 42:6067,1997

42. Kuzniecky RI, Guthrie BL: Stereotactic surgical approach to hypothalamic hamartomas. Epileptic Disord 5:275-80, 2003

43. Mathieu D, Deacon C, Pinard C-A, Kenny B, Duval J: Gamma Knife surgery for hypothalamic hamartomas causing refractory epilepsy: preliminary results from a prospective observational study. J Neurosurg 113 Suppl:215-21, 2010

44. McGonigal A, Sahgal A, De Salles A, Hayashi M, Levivier M, Ma L, et al: Radiosurgery for epilepsy: Systematic review and International Stereotactic Radiosurgery Society (ISRS) practice guideline. Epilepsy Res 137:123-131, 2017

45. Medvid R, Ruiz A, Komotar RJ, Jagid JR, Ivan ME, Quencer RM, et al: Current applications of MRI-guided laser interstitial thermal therapy in the treatment of brain neoplasms and epilepsy: A radiologic and neurosurgical overview. Am J Neuroradiol 36:1998-2006, 2015

46. Mittal S, Mittal M, Montes JL, Farmer J-P, Andermann F: Hypothalamic hamartomas. Part 1. Clinical, neuroimaging, and neurophysiological characteristics. Neurosurg Focus 34:E6, 2013

47. Mittal S, Mittal M, Montes JL, Farmer J-P, Andermann F: Hypothalamic hamartomas. Part 2. Surgical considerations and outcome. Neurosurg Focus 34:E7, 2013

48. Mittal S, Mittal M, Montes JL, Farmer JP, Andermann F: Hypothalamic hamartomas. part 2. surgical considerations and outcome. Neurosurg Focus 34:2013

49. Mullatti N, Selway R, Nashef L, Elwes R, Honavar M, Chandler C, et al: The Clinical Spectrum of Epilepsy in Children and Adults with Hypothalamic Hamartoma.

Epilepsia 44:1310-1319, 2003

50. Munari C, Kahane P, Francione S, Hoffmann D, Tassi L, Cusmai R, et al: Role of the hypothalamic hamartoma in the genesis of gelastic fits (a video-stereo-EEG study).

Electroencephalogr Clin Neurophysiol 95:154-60, 1995

51. Ng YT, Rekate HL, Prenger EC, Wang NC, Chung SS, Feiz-Erfan I, et al: Endoscopic resection of hypothalamic hamartomas for refractory symptomatic epilepsy. Neurology 70:1543-1548, 2008 
52. Ng YT, Rekate HL, Prenger EC, Chung SS, Feiz-Erfan I, Wang NC, et al:

Transcallosal resection of hypothalamic hamartoma for intractable epilepsy. Epilepsia 47:1192-1202, 2006

53. Paillas JE, Roger J, Toga M, Soulayrol R, Salamon G, Dravet C, et al: [Hamartoma of the hypothalamus. Clinical, radiological and histological study. Results of excision]. Rev Neurol (Paris) 120:177-94, 1969

54. Parrent AG, Blume WT: Stereotactic amygdalohippocampotomy for the treatment of medial temporal lobe epilepsy. Epilepsia 40:1408-16, 1999

55. Parvizi J, Le S, Foster BL, Bourgeois B, Riviello JJ, Prenger E, et al: Gelastic epilepsy and hypothalamic hamartomas: neuroanatomical analysis of brain lesions in 100 patients. Brain 134:2960-8, 2011

56. Quiske A, Frings L, Wagner K, Unterrainer J, Schulze-Bonhage A: Cognitive functions in juvenile and adult patients with gelastic epilepsy due to hypothalamic hamartoma. Epilepsia 47:153-8, 2006

57. Régis J, Bartolomei F, de Toffol B, Genton P, Kobayashi T, Mori Y, et al: Gamma knife surgery for epilepsy related to hypothalamic hamartomas. Neurosurgery 47:1343-51; discussion 1351-2, 2000

58. Régis J, Hayashi M, Eupierre LP, Villeneuve N, Bartolomei F, Brue T, et al: Gamma knife surgery for epilepsy related to hypothalamic hamartomas. Acta Neurochir Suppl 91:33-50, 2004

59. Régis J, Lagmari M, Carron R, Hayashi M, McGonigal A, Daquin G, et al: Safety and efficacy of Gamma Knife radiosurgery in hypothalamic hamartomas with severe epilepsies: A prospective trial in 48 patients and review of the literature. Epilepsia 58:60-71, 2017

60. Régis J, Scavarda D, Tamura M, Nagayi M, Villeneuve N, Bartolomei F, et al: Epilepsy related to hypothalamic hamartomas: surgical management with special reference to gamma knife surgery. Childs Nerv Syst 22:881-95, 2006

61. Régis J, Scavarda D, Tamura M, Villeneuve N, Bartolomei F, Brue T, et al: Gamma knife surgery for epilepsy related to hypothalamic hamartomas. Semin Pediatr Neurol 14:73-9, 2007 
62. Rosenfeld J V., Feiz-Erfan I: Hypothalamic Hamartoma Treatment: Surgical Resection With the Transcallosal Approach. Semin Pediatr Neurol 14:88-98, 2007

63. Rosenfeld J V., Harvey AS, Wrennall J, Zacharin M, Berkovic SF: Transcallosal Resection of Hypothalamic Hamartomas, with Control of Seizures, in Children with Gelastic Epilepsy. Neurosurgery 48:108-118, 2001

64. Rosenfeld J V: The evolution of treatment for hypothalamic hamartoma: a personal odyssey. Neurosurg Focus 30:E1, 2011

65. Ryvlin P, Cross JH, Rheims S: Epilepsy surgery in children and adults. Lancet Neurol 13:1114-1126, 2014

66. Ryvlin P, Ravier C, Bouvard S, Mauguire F, Le Bars D, Arzimanoglou A, et al: Positron emission tomography in epileptogenic hypothalamic hamartomas. Epileptic Disord 5:219-27, 2003

67. Scholly J, Staack AM, Kahane P, Scavarda D, Régis J, Hirsch E, et al: Hypothalamic hamartoma: Epileptogenesis beyond the lesion? Epilepsia 58:32-40, 2017

68. Schwab RS, Sweet WH, Mark VH, Kjellberg RN, Ervin FR: Treatment of intractable temporal lobe epilepsy by stereotactic amygdala lesions. Trans Am Neurol Assoc 90:12-9, 1965

69. Schwarzmaier H-J, Eickmeyer F, von Tempelhoff W, Fiedler VU, Niehoff H, Ulrich $\mathrm{SD}$, et al: MR-guided laser-induced interstitial thermotherapy of recurrent glioblastoma multiforme: preliminary results in 16 patients. Eur J Radiol 59:208-15, 2006

70. Shim KW, Park EK, Kim DS: Endoscopic treatment of hypothalamic hamartomas. J Korean Neurosurg Soc 60:294-300, 2017

71. Shirozu H, Masuda H, Ito Y, Sonoda M, Kameyama S: Stereotactic radiofrequency thermocoagulation for giant hypothalamic hamartoma. J Neurosurg 125:812-821, 2016

72. Sonoda M, Masuda H, Shirozu H, Ito Y, Akazawa K, Asano E, et al: Predictors of cognitive function in patients with hypothalamic hamartoma following stereotactic radiofrequency thermocoagulation surgery. Epilepsia 58:1556-1565, 2017

73. Southwell DG, Birk HS, Larson PS, Starr PA, Sugrue LP, Auguste KI: Laser ablative 
therapy of sessile hypothalamic hamartomas in children using interventional MRI: report of 5 cases. J Neurosurg Pediatr 21:460-465, 2018

74. Tandon V, Chandra PS, Doddamani RS, Subianto H, Bajaj J, Garg A, et al: Stereotactic Radiofrequency Thermocoagulation of Hypothalamic Hamartoma Using Robotic Guidance (ROSA) Coregistered with O-arm Guidance-Preliminary Technical Note. World Neurosurg 112:267-274, 2018

75. Trousseau A: Clinique Médicale de l'Hôtel-Dieu de Paris. Paris: J-B Bailière, 1873

76. Valdueza JM, Cristante L, Dammann O, Bentele K, Vortmeyer A, Saeger W, et al: Hypothalamic hamartomas: with special reference to gelastic epilepsy and surgery. Neurosurgery 34:949-58; discussion 958, 1994

77. Valentin A, Lazaro M, Mullatti N, Cervantes S, Malik I, Selway RP, et al: Cingulate epileptogenesis in hypothalamic hamartoma. Epilepsia 52:2011

78. van Tonder L, Burn S, Iyer A, Blair J, Didi M, Carter M, et al: Open resection of hypothalamic hamartomas for intractable epilepsy revisited, using intraoperative MRI.

Child's Nerv Syst 34:1663-1673, 2018

79. Wei PH, An Y, Fan XT, Wang YH, Yang YF, Ren LK, et al:

Stereoelectroencephalography-Guided Radiofrequency Thermocoagulation for Hypothalamic Hamartomas: Preliminary Evidence. World Neurosurg 114:e1073e1078, 2018

80. Wright JM, Staudt MD, Alonso A, Miller JP, Sloan AE: A novel use of the NeuroBlate SideFire probe for minimally invasive disconnection of a hypothalamic hamartoma in a child with gelastic seizures. J Neurosurg Pediatr 21:302-307, 2018

81. Xu DS, Chen T, Hlubek RJ, Bristol RE, Smith KA, Ponce FA, et al: Magnetic resonance imaging-guided laser interstitial thermal therapy for the treatment of hypothalamic hamartomas: A retrospective review. Clin Neurosurg 83:1183-1191, 2018

82. Xu DS, Chen T, Hlubek RJ, Bristol RE, Smith KA, Ponce FA, et al: Magnetic Resonance Imaging-Guided Laser Interstitial Thermal Therapy for the Treatment of Hypothalamic Hamartomas: A Retrospective Review. Neurosurgery:2018

83. Yao H, Luo S, Ma Z, Zhang Y, Jia G: [Complications after transcallosal transseptal 
interforniceal resection of hypothalamic hamartoma: analysis of 37 cases]. Zhonghua

1

2

3

4

5

6

7

8

9

10

11

12

13

14

15

16

17

18

19

20

21

22

23

24

25

26

27

28

29

30

31

32

33

34

35

36

37

38

39

40

41

42

43

44

45

46

47

48

49

50

51

52

53

54

55

56

57

58

59

60

61

62

63

64

65

Yi Xue Za Zhi 89:898-900, 2009 


\begin{tabular}{|c|c|c|c|c|c|}
\hline & $\begin{array}{l}\text { Rounded } \\
\text { seizure } \\
\text { control } \\
\text { rate }\end{array}$ & $\begin{array}{l}\text { Rounded } \\
\text { seizure } \\
\text { free rate }\end{array}$ & $\begin{array}{c}\text { Rounded } \\
\text { complication } \\
\text { rate }\end{array}$ & $\begin{array}{l}\text { Rounded } \\
\text { number of } \\
\text { patients } \\
\text { reported }\end{array}$ & $\begin{array}{l}\text { Main type of } \\
\text { complication }\end{array}$ \\
\hline $\begin{array}{c}\text { Pterional } \\
\text { approach }^{51,67}\end{array}$ & $90 \%$ & $55 \%$ & $50 \%$ & 30 & $\begin{array}{c}\text { Third nerve palsy } \\
\text { Hemiplegia } \\
\text { Diabetes insipidus } \\
\text { Hyperphagia } \\
\text { Memory } \\
\text { impairment } \\
\end{array}$ \\
\hline $\begin{array}{c}\text { Transcallosal } \\
\text { approach }^{51,55,65}\end{array}$ & $90 \%$ & $50-55 \%$ & $10 \%$ & 70 & $\begin{array}{c}\text { Memory } \\
\text { impairment } \\
\text { Thalamic } \\
\text { infarction } \\
\end{array}$ \\
\hline $\begin{array}{c}\text { Endoscopic } \\
\text { resection }^{2,19,45,54}\end{array}$ & $80 \%$ & $45-50 \%$ & $8 \%$ & 25 & $\begin{array}{c}\text { Memory } \\
\text { impairment } \\
\text { Hemiperesis }\end{array}$ \\
\hline $\begin{array}{c}\text { Stereotactic } \\
\text { radiosurgery } \\
16,47,60\end{array}$ & $65 \%$ & $25 \%$ & $0 \%$ & 80 & 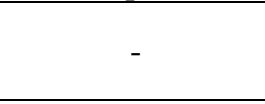 \\
\hline $\begin{array}{c}\text { LiTT } \\
\text { (standard) }^{21,22,85}\end{array}$ & $80 \%$ & $45 \%$ & $25 \%$ & 115 & $\begin{array}{c}\text { Memory } \\
\text { impairment } \\
\text { Hyperphagia }\end{array}$ \\
\hline $\begin{array}{l}\text { LiTT (fMRI } \\
\text { targeted) }\end{array}$ & $90 \%$ & $90 \%$ & $0 \%$ & 35 & 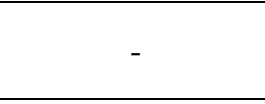 \\
\hline $\begin{array}{c}\text { Stereotactic RF- } \\
\text { TC }^{39} \\
\end{array}$ & $80 \%$ & $70 \%$ & $2 \%$ & 100 & Diabetes insipidus \\
\hline $\begin{array}{c}\text { Endoscopic laser } \\
\text { and RF-TC }\end{array}$ & $80 \%$ & $60 \%$ & $8 \%$ & 135 & $\begin{array}{l}\text { Diabetes insipidus } \\
\text { Hemiplegia } \\
\text { Third nerve palsy }\end{array}$ \\
\hline
\end{tabular}

Table 1: overview of the different surgical approaches for the treatment of hypothalamic hamartomas. Rates and numbers are rounded based on the literature. Exact rates are described in the respective sections. RF-TC: radiofrequency thermocoagulation; LiTT: laser interstitial thermotherapy. 

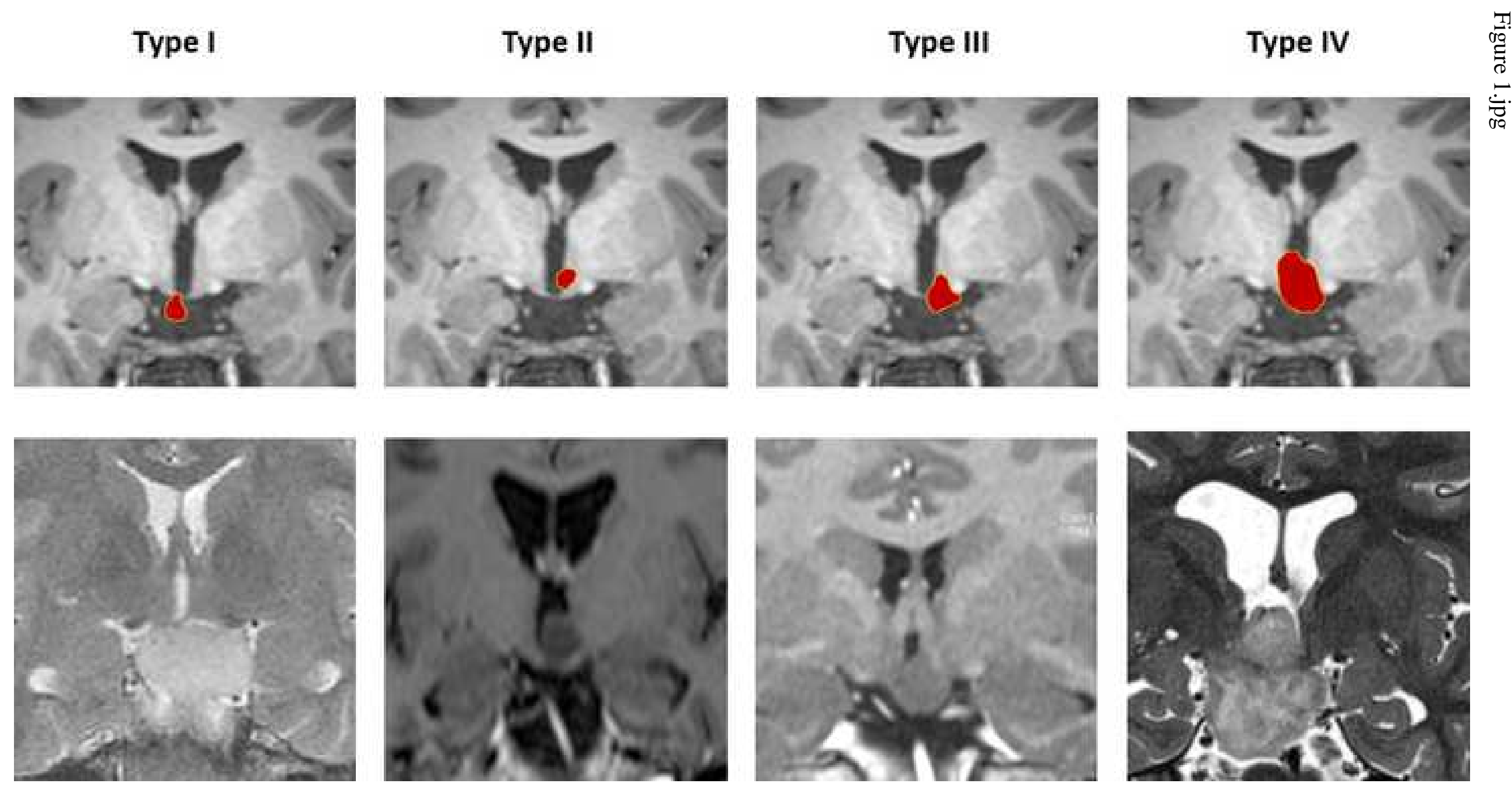
Pterional Approach

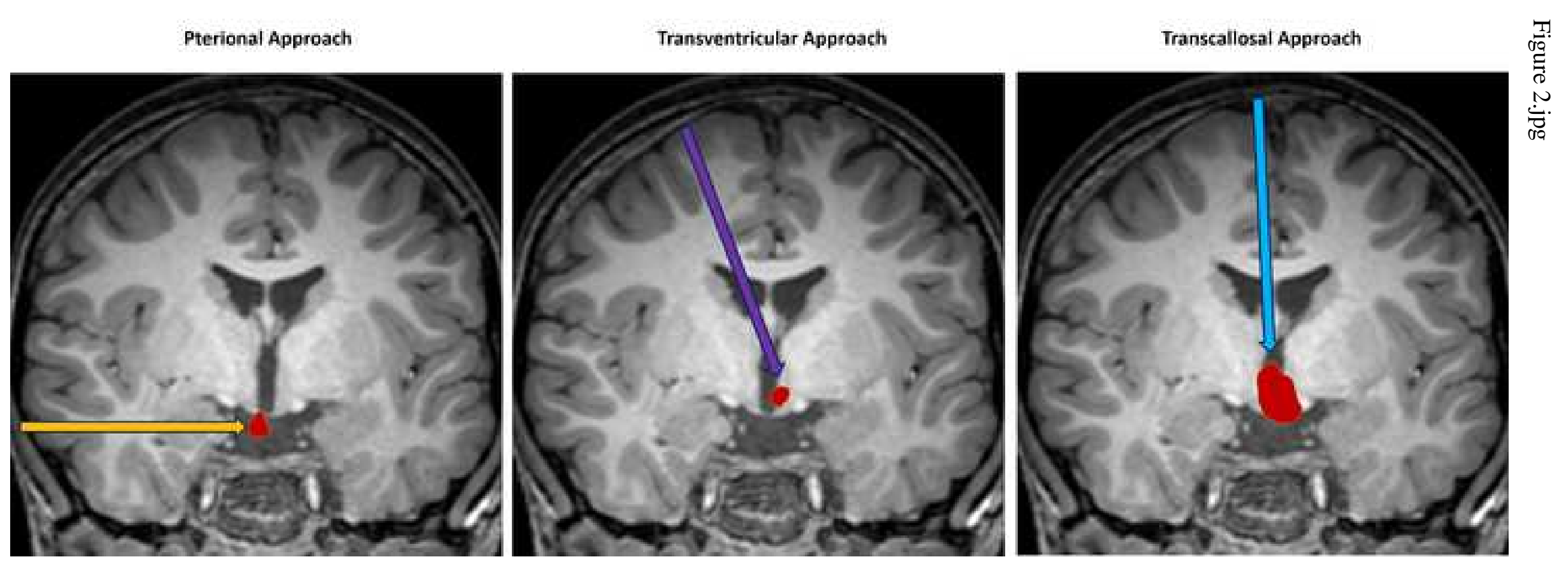

Transventricular Approach

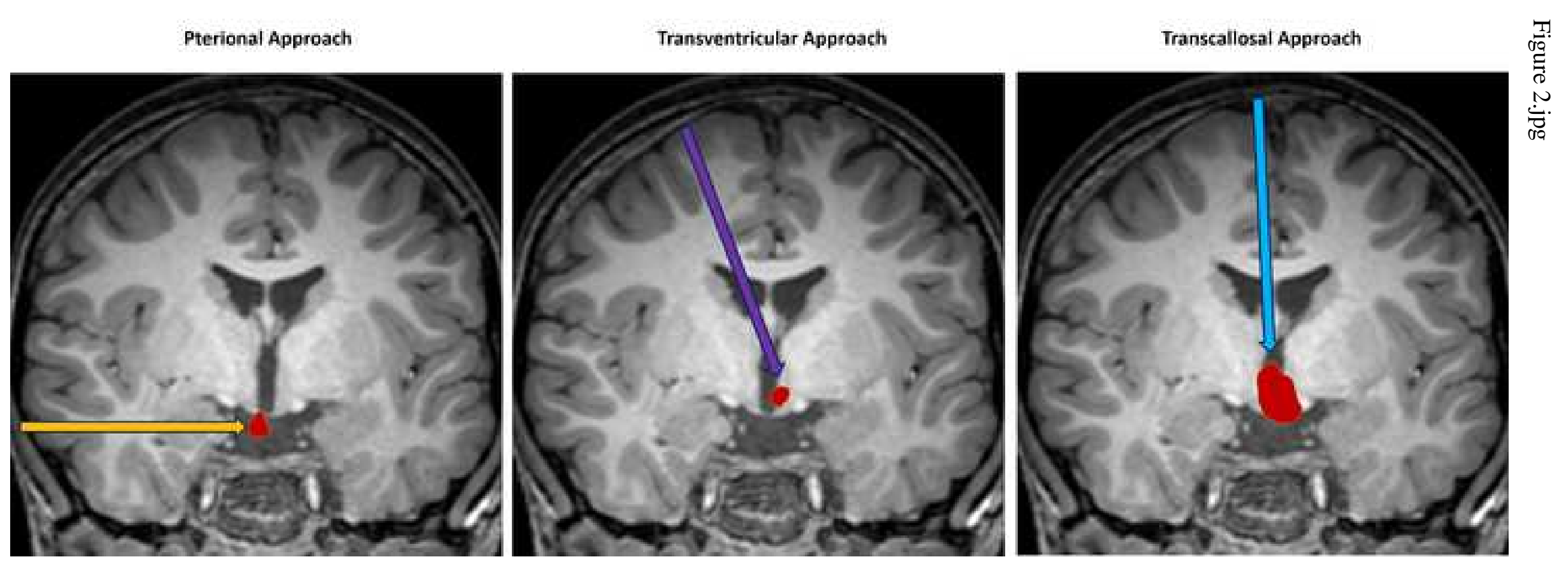

Transcallosal Approach

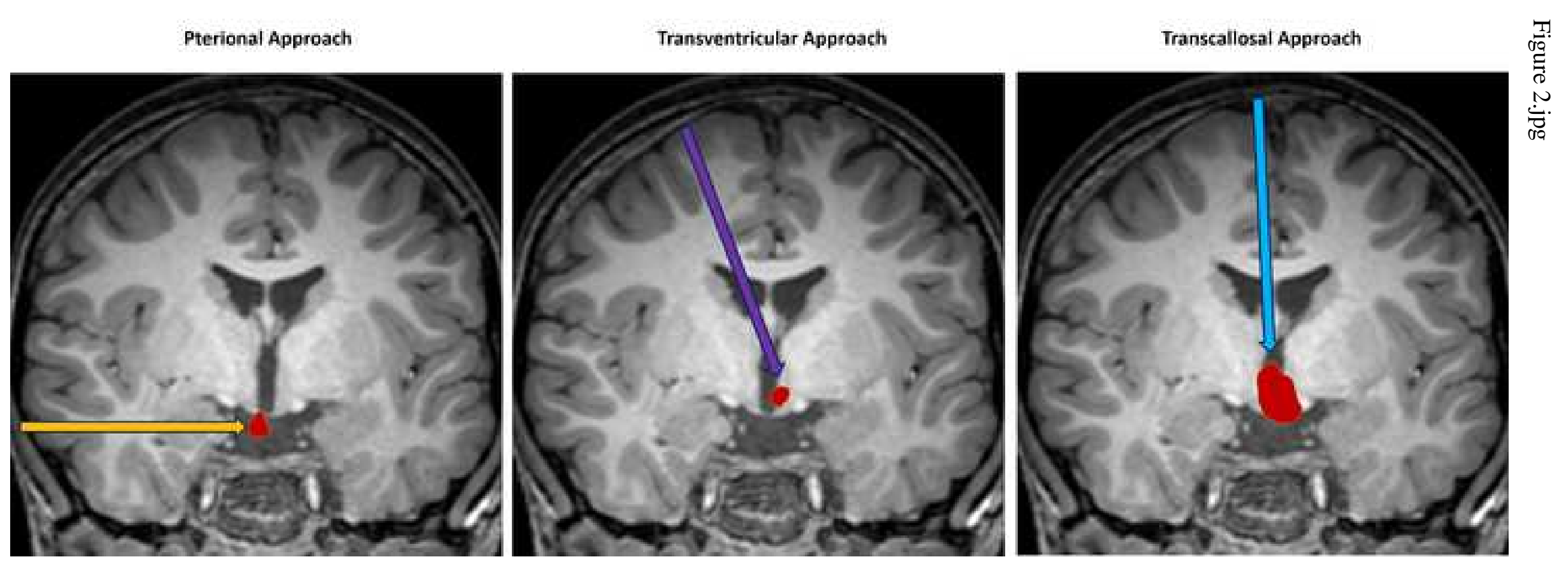

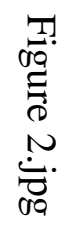

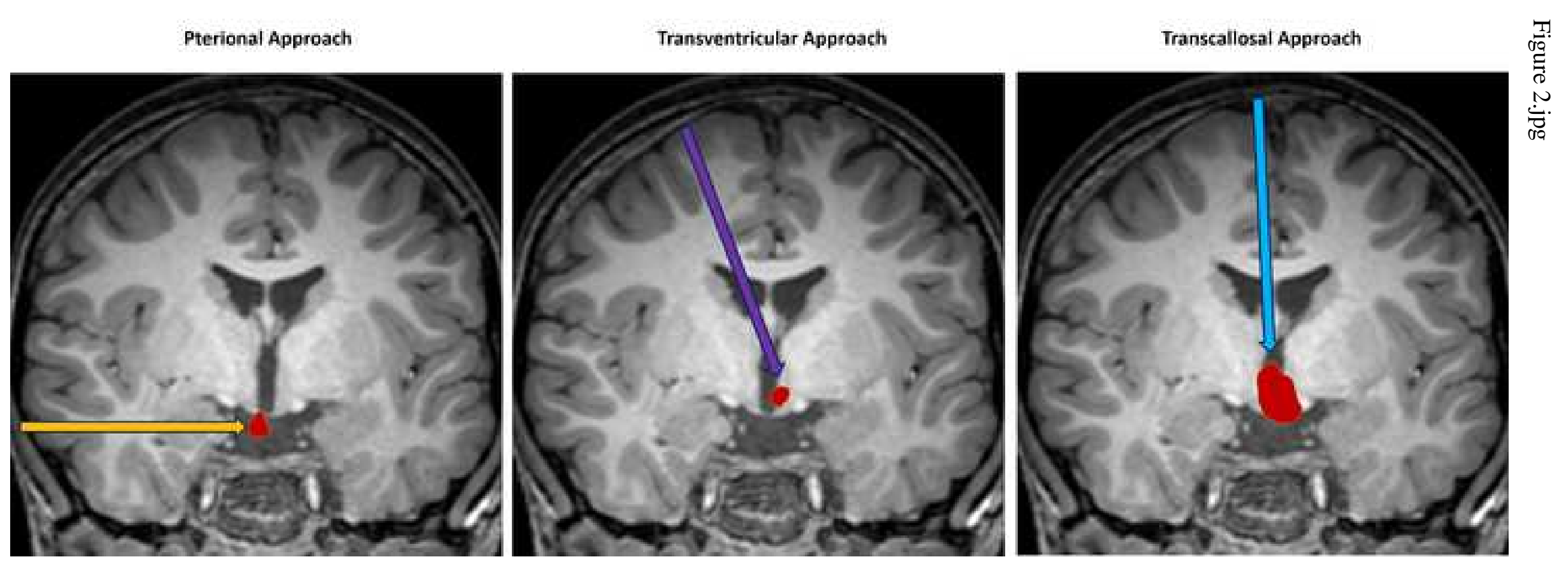



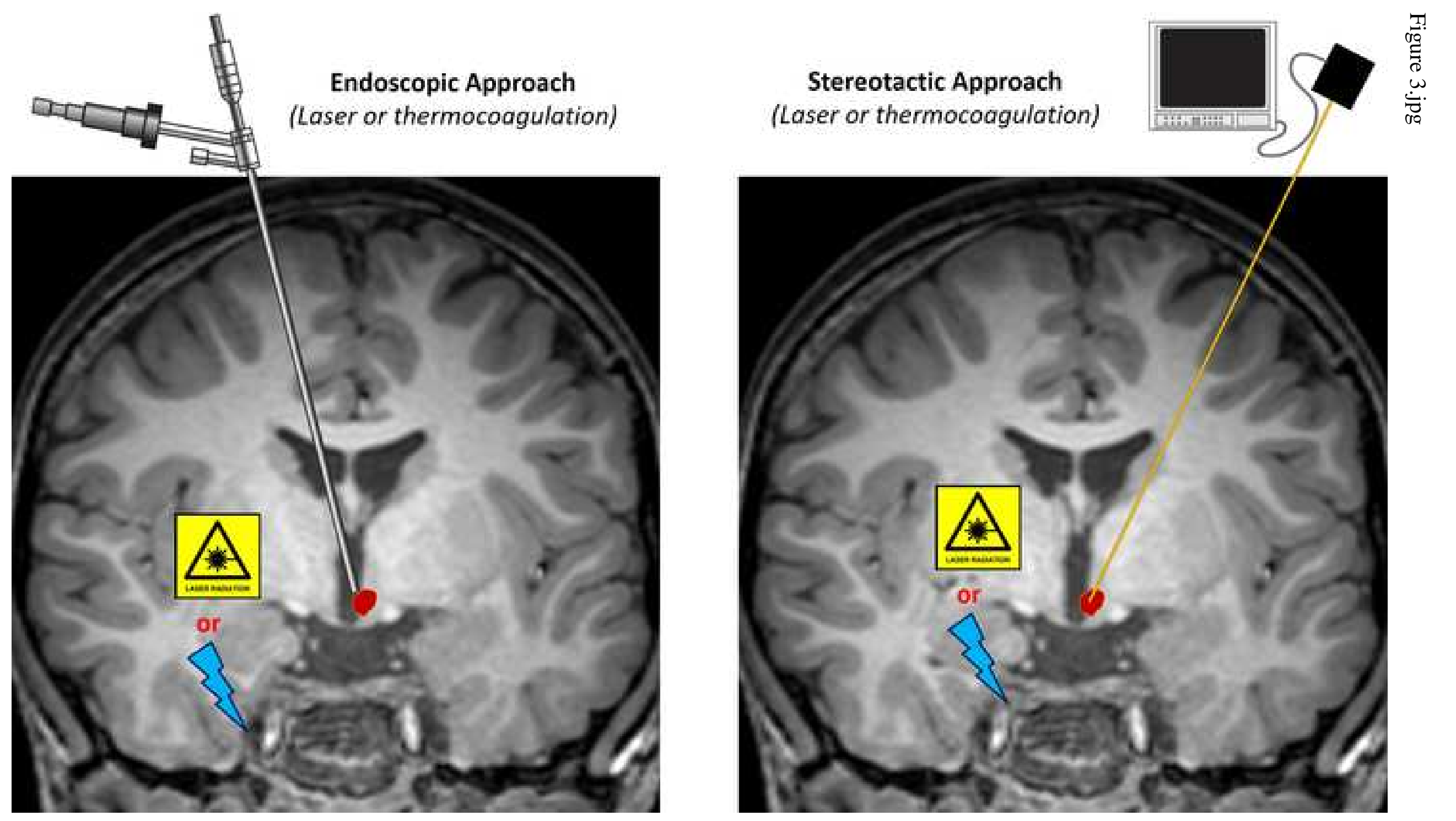


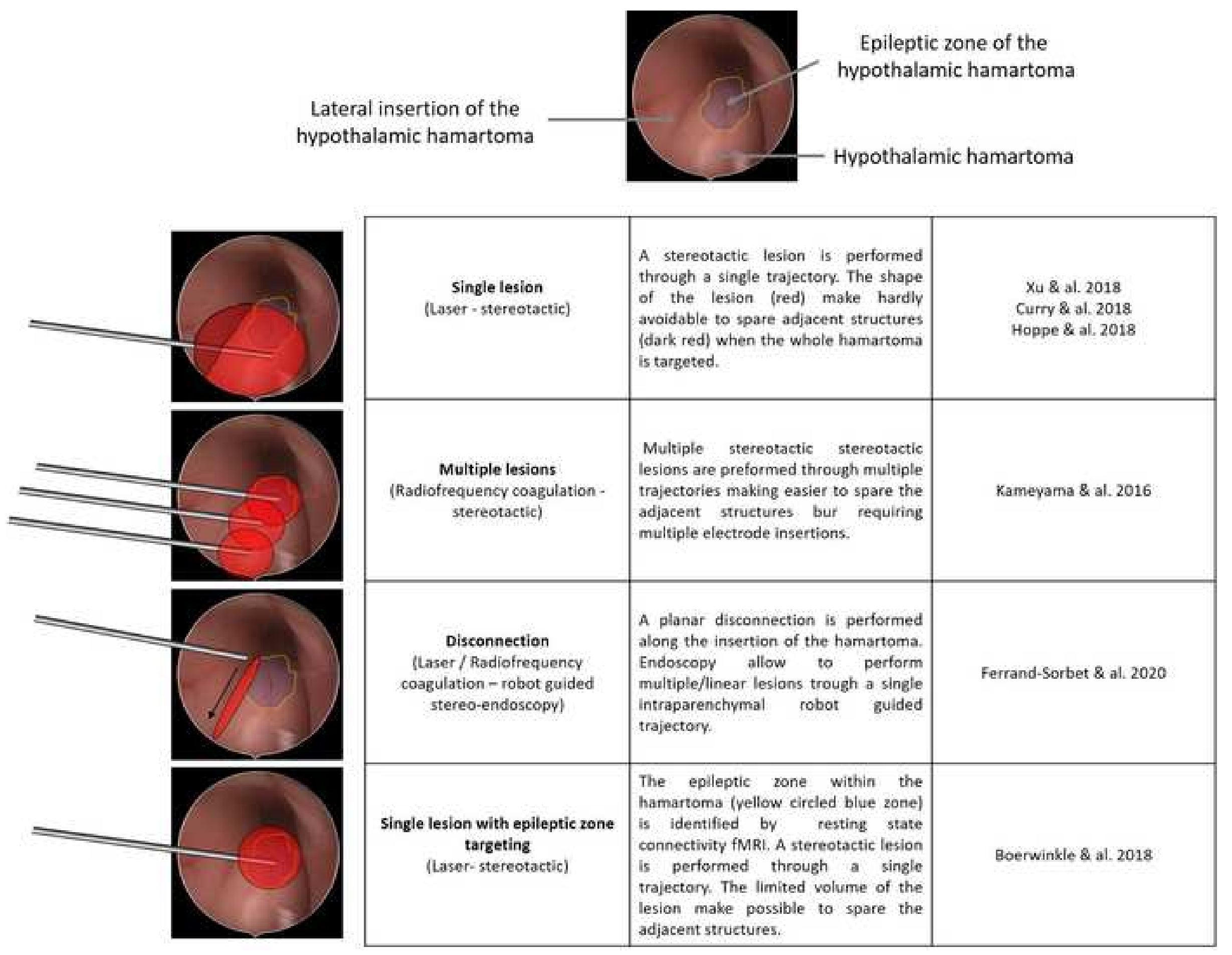


Click here to access/download Video Thermocoag Hamartomas.mov 
Click here to access/download Video

Laser Hamartomas.mov 